\title{
BMJ Global Health How can we strengthen the Joint External Evaluation?
}

To cite: Stowell D, Garfield R. How can we strengthen the Joint External Evaluation?BMJ Global Health 2021;6:e04545. doi:10.1136/ bmjgh-2020-004545

Handling editor Seye Abimbola

Received 24 November 2020

Revised 6 April 2021

Accepted 16 April 2021
Check for updates

C Author(s) (or their employer(s)) 2021. Re-use permitted under CC BY-NC. No commercial re-use. See rights and permissions. Published by BMJ.

Center for Global Health, Centers for Disease Control and Prevention, Atlanta, Georgia, USA

Correspondence to

Daniel Stowell;

dstowell@cdc.gov

\section{INTRODUCTION}

The COVID-19 pandemic has raised questions about the utility of the International Health Regulations (IHR) and the effectiveness of the Joint External Evaluation (JEE) for strengthening global health security. ${ }^{1}$ If we are to embark on further revisions to the JEE for measuring global health security, we need to re-examine its purpose and limitations.

\section{STRENGTHS AND LIMITATIONS}

The JEE established four important norms: ${ }^{2}$ (1) normalising a transparent process to examine and report on a country's health security strengths and weaknesses; (2) setting standard definitions and scoring a country's capacities in 19 technical areas; (3) involving governments and donors in strengthening those capacities across sectors and (4) prioritising opportunities for capacity development based on existing gaps. Over 110 countries, ${ }^{3}$ more than half of all WHO Member States have participated in the JEE. These assessments identified many critical health security gaps and actions to take.

In 2018, WHO released the JEE Edition 2 (JEE E2) to strengthen the tool based on country experiences and subject matter expert feedback. The updates maintained the original structure, while adding five indicators, merging four indicators, renaming three technical areas and clarifying interpretation of various attributes. ${ }^{4}$ Regional epidemics and the COVID-19 pandemic have highlighted gaps, some of which are not currently well represented in JEE E2. Improving measurement may involve changes to the JEE in these areas:

- Subnational capacity - the JEE is focused on national capacities, but national capacities are reliant on effective subnational or intermediate capacities. JEE E2 explicitly includes subnational
Summary box

The COVID-19 pandemic raises fundamental questions about the appropriateness of the International Health Regulations and the effectiveness of the Joint External Evaluation (JEE) for strengthening global health security.

- In the wake of COVID-19, revision of JEE tool should be based on an understanding of the purpose, use and limitations of the measurement tool.

- Successfully strengthening the tool will necessitate countries to take action on the results of the assessment as well as addressing certain strategic, technical and operational considerations in the next edition of the tool.

capacities in National legislation, policy and financing (P.1.2), Food safety (P.5.1), Immunisation (P.7.1), National laboratory system (D.1.1), Surveillance (D.2.1), Reporting (D.3.2), Human resources (D.4.2-4), Emergency preparedness (R.1.1-2), Emergency response operations (R.2.1-3), Linking public health and security authorities (R.3.1) and Risk communication (R.5.2, R.5.4), but lacks articulated subnational capacities in other technical areas and a consistent approach across them.

- Safe health facilities-health systems cannot function when health workers are unsafe. Infection prevention and control (IPC) appears in JEE E2 as an indicator in Antimicrobial Resistance (P.3.3). One indicator is not enough and, therefore, Wilkason and colleagues propose that a new technical area should be created for safe health facilities or IPC to emphasise the importance of healthcare worker safety in global preparedness efforts. ${ }^{5}$

- Health equity and groups that have been marginalised-there is increasing evidence that groups which have been economically or socially marginalised, including racial and ethnic minorities, 
are disproportionately affected by COVID-19. ${ }^{6} 7$ WHO's Commission on the Social Determinants of Health, Closing the Gap, articulated an expansive plan to address the complex web of determinants that contribute to health inequalities that can further fuel many infectious diseases. ${ }^{8}$ Quinn and Kumar propose that countries account for health inequalities in preparedness and response. ${ }^{9}$ Health equity is not currently addressed in the JEE E2, but evidence suggests that it could be considered.

- Case management-there is a critical link between case management, healthcare and health security. Case management appears in the JEE E2 in Medical Countermeasures and Personnel Deployment (R.4.3). Kluge et al propose that health security investments support universal health coverage by avoiding health crises that prevent patients from accessing healthcare (eg, health workforce diverted from regular care to focus on crisis response, health workforce is susceptible to infection during an infectious disease crisis or patients' fear of contamination leads them avoid regular care). ${ }^{10}$ These linkages may warrant further exploration in the JEE.

\section{CONCLUSION}

How to include these themes in the JEE is not yet clear. The JEE tool is mainly focused on measurable capacities. How a country uses its capacities and governs during a crisis is far more difficult to measure, although it may be of similar importance. Simulation Exercises, Intra-Action and After-Action Reviews and other tools can assist in assessing this.

Many countries have struggled to implement corrective actions following a JEE, in part, due to the comprehensive nature of the assessment tool and the overwhelming number of activities that need to be completed. As we expand or change the tool, countries will need clear guidance on prioritising a small number of activities that can be completed with existing resources. In addition, any expansion or changes to the tool should be balanced against the already heavy data collection and reporting burden on countries. New technical areas, indicators or criteria will need to draw from country experiences with COVID-19 in addition to country capacity built since the introduction of the JEE half a decade ago.

A recent report from Independent Oversight and Advisory Committee on WHO's response to COVID-19 has called for a review of the JEE and other existing IHR tools. ${ }^{11}$
We agree that assessment of country capacity can be strengthened, but the need for countries to take action on the results of the assessment should be a primary focus of improving the tools.

Contributors DS conceived of and cowrote the comment. RG cowrote the comment. DS served as the Coprincipal Investigator on the CDC-WHO IHR Collaborating Centre. DS also served as the CDC focal point to WHO for coordinating the roll out of the Joint External Evaluation (JEE), provided technical input into JEE guidance documents and provided direct support to countries undergoing a JEE. RG has served as member of nine JEE missions. RG is a senior advisor overseeing CDC contributions to the IHR Monitoring and Evaluation Framework, including the JEE.

Funding The authors have not declared a specific grant for this research from any funding agency in the public, commercial or not-for-profit sectors.

Competing interests None declared.

Patient consent for publication Not required.

Provenance and peer review Not commissioned; externally peer reviewed.

\section{Data availability statement There are no data in this work.}

Open access This is an open access article distributed in accordance with the Creative Commons Attribution Non Commercial (CC BY-NC 4.0) license, which permits others to distribute, remix, adapt, build upon this work non-commercially, and license their derivative works on different terms, provided the original work is properly cited, appropriate credit is given, any changes made indicated, and the use is non-commercial. See: http://creativecommons.org/licenses/by-nc/4.0/.

\section{ORCID iDs}

Daniel Stowell http://orcid.org/0000-0002-4653-6113

Richard Garfield http://orcid.org/0000-0002-1039-8134

\section{REFERENCES}

1 Independent Oversight and Advisory Committee for the WHO Health Emergencies Programme. Looking back to move forward. Geneva, 2020.

2 Bell E, Tappero JW, ljaz K, et al. Joint external EvaluationDevelopment and scale-up of global Multisectoral health capacity evaluation process. Emerg Infect Dis 2017;23.

3 WHO. Joint External Evaluation Mission Reports [Internet]. Available: https://www.who.int/ihr/procedures/mission-reports/en/ [Accessed 23 Nov 2020].

4 Kandel N, Sreedharan R, Chungong S, et al. The joint external evaluation tool, second edition: changes, interpretation, and use. Health Secur 2019;17:248-50.

5 Wilkason C, Lee C, Sauer LM, et al. Assessing and reducing risk to healthcare workers in outbreaks. Health Secur 2020;18:205-11.

6 DBG T, Shah A, Doubeni CA. The disproportionate impact of COVID-19 on racial and ethnic minorities in the United States. Clin Infect Dis 2021;72.

7 Public Health England. Disparities in the risk and outcomes of COVID-19, 2020

8 Commission on Social Determinants of Health. Closing the gap in a generation: health equity through action on the social determinants of health [Internet]. Geneve, 2008. Available: https://www.who.int/ publications/i/item/WHO-IER-CSDH-08.1 [Accessed 23 Nov 2020].

9 Quinn SC, Kumar S. Health inequalities and infectious disease epidemics: a challenge for global health security. Biosecur Bioterror 2014;12:263-73.

10 Kluge H, Martín-Moreno JM, Emiroglu N, et al. Strengthening global health security by embedding the International health regulations requirements into National health systems. BMJ Glob Health 2018;3:e000656.

11 Independent Oversight Advisory Committee for the WHO Health Emergencies Programme. IOAC Interim report on WHO's response to COVID-19, 2021. 